\title{
WestVirginiaUniversity
}

THE RESEARCH REPOSITORY @ WVU

Graduate Theses, Dissertations, and Problem Reports

2021

\section{Analyzing and Measuring Petrophysical Properties of Marcellus Shale}

Yahia Mustafa Yassin Mustafa

West Virginia University, ymm0002@mix.wvu.edu

Follow this and additional works at: https://researchrepository.wvu.edu/etd

Part of the Petroleum Engineering Commons

\section{Recommended Citation}

Mustafa, Yahia Mustafa Yassin, "Analyzing and Measuring Petrophysical Properties of Marcellus Shale" (2021). Graduate Theses, Dissertations, and Problem Reports. 10207.

https://researchrepository.wvu.edu/etd/10207

This Problem/Project Report is protected by copyright and/or related rights. It has been brought to you by the The Research Repository @WVU with permission from the rights-holder(s). You are free to use this Problem/Project Report in any way that is permitted by the copyright and related rights legislation that applies to your use. For other uses you must obtain permission from the rights-holder(s) directly, unless additional rights are indicated by a Creative Commons license in the record and/ or on the work itself. This Problem/Project Report has been accepted for inclusion in WVU Graduate Theses, Dissertations, and Problem Reports collection by an authorized administrator of The Research Repository @ WVU. For more information, please contact researchrepository@mail.wvu.edu. 
Graduate Theses, Dissertations, and Problem Reports

2021

Analyzing and Measuring Petrophysical Properties of Marcellus Shale

Yahia Mustafa Yassin Mustafa

Follow this and additional works at: https://researchrepository.wvu.edu/etd

Part of the Petroleum Engineering Commons 
Analyzing and Measuring Petrophysical Properties of Marcellus Shale

\author{
Yahia Mustafa
}

Report submitted

to the Statler College of Engineering and Mineral Resources

at West Virginia University

in partial fulfillment of the requirements for the degree of

\author{
Master of Science in \\ Petroleum and Natural Gas Engineering \\ Kashy Aminian, Ph.D., Chair. \\ Samuel Ameri, M.S. \\ Mehrdad Zamirian, Ph.D \\ Department of Petroleum and Natural Gas Engineering \\ Morgantown, West Virginia \\ 2021
}

Keyword: analyzing Petrophysical Properties of The Shale

Copyright 2021 Yahia Mustafa 


\section{Abstract \\ Analyzing and Measuring Petrophysical Properties of Marcellus Shale}

\section{Yahia Mustafa}

Unconventional oil and natural gas play a key role in our nation's future. The U.S. has vast reserves of such resources that are commercially viable as a result of advances in horizontal drilling and hydraulicfracturing technology. These technologies enable greater access to oil and natural gas in shale formations. Responsible development of America's shale gas resources offers important economic, energy security, and environmental benefits. Hydraulic fracturing and horizontal drilling apply the latest technologies and make it commercially viable to recover shale gas and oil.

In order to estimate the original gas-in-place, predict the production rates, and optimize the hydraulic fracturing treatments, reliable values of the shale key petrophysical properties including permeability, porosity, and adsorption characteristics are necessary. The quantification of the shale petrophysical properties however is challenging due to complex nature of the shale. Shale is an organic-rich, naturally fractured formation with ultra-low matrix permeability. The gas is stored in the limited pore space of the shale matrix and may be adsorbed on the organic material. It is not practical to measure the permeability of the shale samples by the conventional laboratory steady-state technique due to extremely low flow rates

and the length time required for establishing steady-state conditions. Consequently, different unsteady-state laboratory techniques have been introduced for measuring the permeability of the rock samples from extremely low permeability formations. The most common techniques include GRI, pressure pulse decay, and high-pressure mercury injection. However, the measured permeability values by these techniques often suffer from large margin of uncertainty and non-uniqueness.

In this study the data was obtained from two different shale samples by using the Precision Petrophysical Analysis Laboratory (PPAL). Which utilizes highly accurate pressure and pressure-differential transducers, and it is capable of measuring the permeability in a nano-Darcy range under steady-state conditions. The entire system is enclosed in a clear Lexan container to assure temperature stability. PPAL allows a measurement to be performed on the core plug under confining pressure up to 10,000 psi and the pore pressure up to 1,500 psi. this data has been analyzed and the absolute permeability of the two shale samples was calculated, and the adsorption and desorption effect on the permeability were evaluated using Helium and Nitrogen, finally the impact of pore pressure and net stress on permeability and porosity using Nitrogen were also evaluated. The pore pressure and stress were found to have a significant impact on the measured permeability values. Furthermore, the permeability exhibited hysteresis with increasing and decreasing stress values, the porosity measurements using Nitrogen were not significantly impacted by the stress. Finally, a comparison was performed between the two samples. 


\section{Acknowledgement}

I would like to express my deepest appreciations to my research advisor Dr. Kashy Aminian for his continuous support, guidance, assistance, and encouragement throughout my graduate program. His support, help and professional assistance made me completed my studies are numerous and valuable.

My sincere appreciation and thanks to Professor. Sam Ameri, chair of Petroleum and Natural Gas Engineering Department. For his continues support, motivation, and guidance. I would like also to express my deepest appreciation for the knowledge and experience provided to me, He has always been like a father to me throughout my study.

I would also like to express my deepest thanks and appreciation to Dr. Mehrdad Zamirian. For his help, assistance, passionate participation, and input, throughout my graduate program.

Furthermore, special thanks to all family of Petroleum and Natural Gas Engineering Department especially to Ms. Adriane Matheny for her friendly ambience and continuous help.

My Sincere appreciation also goes to my family and friends for their unconditional love, support, advice, and prayers.

I cannot express enough love and appreciation for my beloved father and mother for their support. The reason of what I achieved today is because of you both. 


\section{Table of content}

Abstract

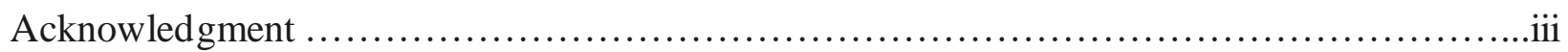

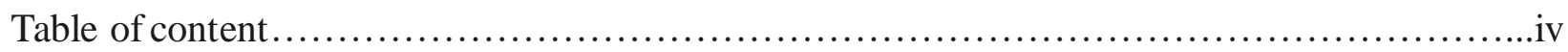

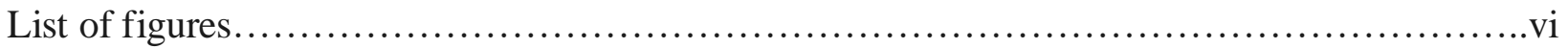

Chapter 1. Introduction ..........................................................

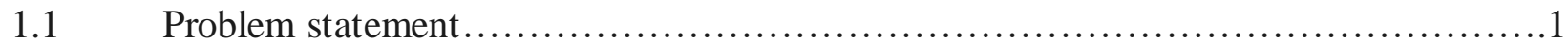

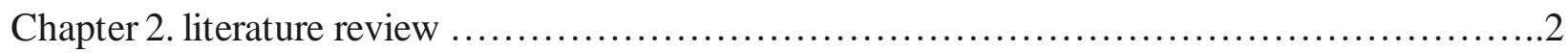

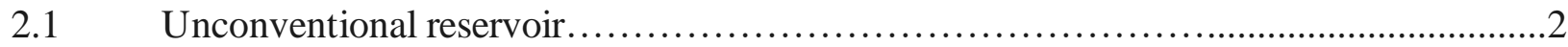

2.2 Precision Petrophysical Analysis Laboratory (PPAL ..............................

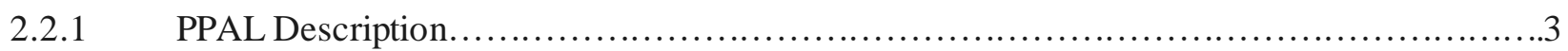

2.2.2 PPAL Operation.............................................................

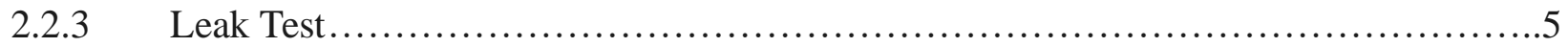

2.2.4 Line Volume Measurements............................................5

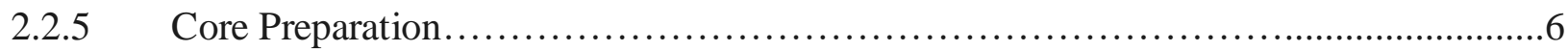

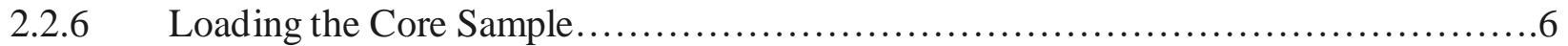

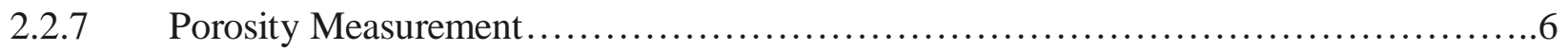

2.2.8 Permeability Measurement.................................................

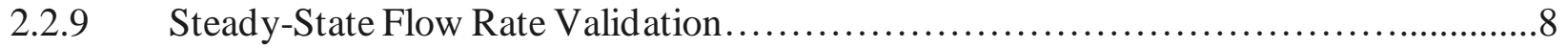

2.3 Klinkenberg Correction.......................................................

2.3.1 Double Slippage Correction............................................ 10

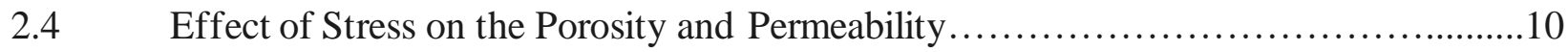

Chapter 3. Objective and Methodology ................................................ 12

3.1 Impact of the Pore Pressure on Permeability (SlippagEffect)....................... 12

3.2 Adsorption/Desorption Effect on Permeability .............................. 12

Stress Effect on Permeability and Porosity....................................... 13

Chapter 4. Results and Discussions............................................. 14

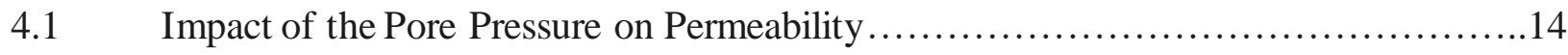


4.2 Absolute Permeability Determination............................................ 16

4.3 Adsorption/Desorption Effect on Permeability .....................................16

4.4 Stress Effect on Permeability using Nitrogen.......................................18

4.5 Stress Effect on Porosity using Nitrogen.......................................... 19

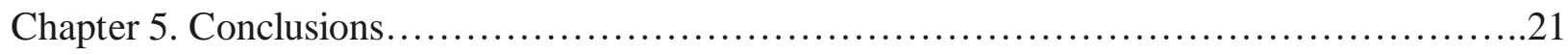

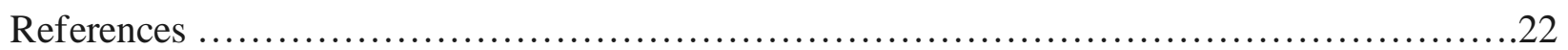




\section{List of Figures}

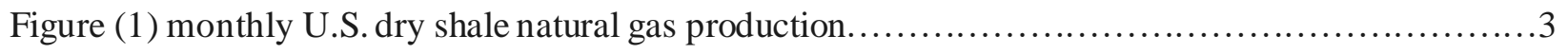

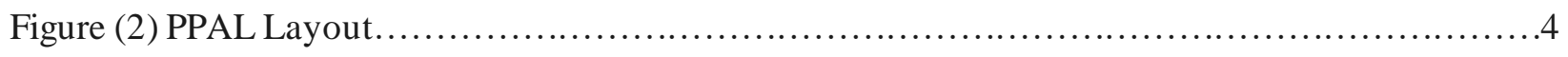

Figure (3) Gas pressure (slippage) effect on permeability using Helium, (MSEEL)....................14

Figure (4) Adsorption/Desorption effect on permeability using Nitrogen, (MSEEL) ...................15

Figure (5) Adsorption/Desorption effect on permeability using Helium and Nitrogen, (F2HA)............15

Figure (6) Double slippage correction on gas permeability using Helium, (MSEEL)...................16

Figure (7) Adsorption/Desorption Effect on Permeability using Nitrogen, (MSEEL) ...................17

Figure (8) Double slippage correction on Helium and Nitrogen measurements, (F2HA)................17

Figure (9) Stress Effect on Permeability using Nitrogen, (MSEEL) $\ldots \ldots \ldots \ldots \ldots \ldots \ldots \ldots \ldots \ldots \ldots \ldots \ldots 18$

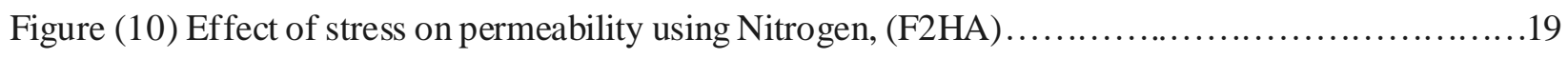

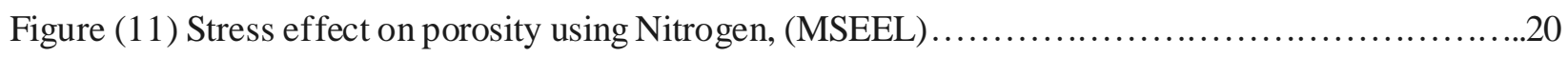

Figure (12) Stress effect on porosity using Nitrogen, (F2HA) ................................. 20 


\section{Chapter 1}

\section{introduction}

\subsection{Problem statement}

hydraulic fracturing and horizontal well technology have revealed considerable reserves of hydrocarbon contained in shale formation, Unconventional reservoirs, such as the Marcellus Shale play a big role in hydrocarbon production in the United States.

The petrophysical properties of the unconventional reservoirs, including permeability and porosity along with adsorption characteristics, are the keys factor to estimate the original gas -in place, predicting the production rates, and optimizing the hydraulic fracturing treatments. determination of the key petrophysical properties in shale reservoirs remain challenging due to the complex nature of the shale gas reservoirs. The permeability of conventional reservoirs, which have permeability values in milli-Darcy range, can be accurately measured by the steady-state laboratory techniques. By contrast, the unconventional formations such as shales typically have permeability values in nano-Darcy range. It is not practical to measure the permeability of the shale samples by steady state techniques because of very low flow rates and length of time required to reach the steady state condition. Therefore, unsteady state methods such as GRI and pressure pulse decay which are faster and can measure permeability values as low as 10-9 Darcy have been extensively used to estimate permeability of the shale samples. However, the unsteady state measurements results cannot be corrected for the pore pressure or stress and subsequently yield inconsistent values (Sondergeld et al. 2010; Tinni et al., 2012; Zamirian et al. 2014a). Therefore, as stated before, the limitations of these techniques have led to the development of a new approach to measure the characterizations and petrophysical properties of the unconventional reservoir, which is the Precision Petrophysical Analysis Laboratory (PPAL).

In this study the data for two shale samples was obtained using (PPAL) has been analyzed to calculate absolute permeability and the impact of pore pressure and stress effect on permeability and porosity using Nitrogen, finally a comparison was performed between the two samples. 


\section{Chapter 2}

\section{Literature Review}

\subsection{Unconventional reservoir}

Production from unconventional petroleum reservoirs includes petroleum from shale, coal, tight-sand and oil-sand. These reservoirs contain enormous quantities of oil and natural gas but pose a technology challenge to both geoscientists and engineers to produce economically on a commercial scale. These reservoirs store large volumes and are widely distributed at different stratigraphic levels and basin types, offering long-term potential for energy supply. Most of these reservoirs are low permeability and porosity that need enhancement with hydraulic fracture stimulation to maximize fluid drainage. Production from these reservoirs is increasing with continued advancement in geological characterization techniques and technology for well drilling, logging, and completion with drainage enhancement. Currently, Australia, Argentina, Canada, Egypt, USA, and Venezuela are producing natural gas from low permeability reservoirs: tight-sand, shale, and coal (CBM). Canada, Russia, USA, and Venezuela are producing heavy oil from oil sand. USA is leading the development of techniques for exploring, and technology for exploiting unconventional gas resources.

The main focus is on source-reservoir-seal shale petroleum plays. In these tight rocks petroleum resides in the micro-pores as well as adsorbed on and in the organics. Shale has very low matrix permeability (nanodarcies) and has highly layered formations with differences in vertical and horizontal properties, vertically non-homogeneous and horizontally anisotropic with complicate natural fractures. Understanding the rocks is critical in selecting fluid drainage enhancement mechanisms; rock properties such as where shale is clay or silica rich, clay types and maturation, kerogen type and maturation, permeability, porosity, and saturation. Most of these plays require horizontal development with large numbers of wells that require an understanding of formation structure, setting and reservoir character and its lateral extension.

During the past decade, unconventional shale and tight-sand gas plays have become an important supply of natural gas in the US, and now in shale oil as well. as a consequence, interest to assess and explore these plays is rapidly spreading worldwide. The high production potential of shale petroleum resources has contributed to a comparably favorable outlook for increased future petroleum supplies globally. 


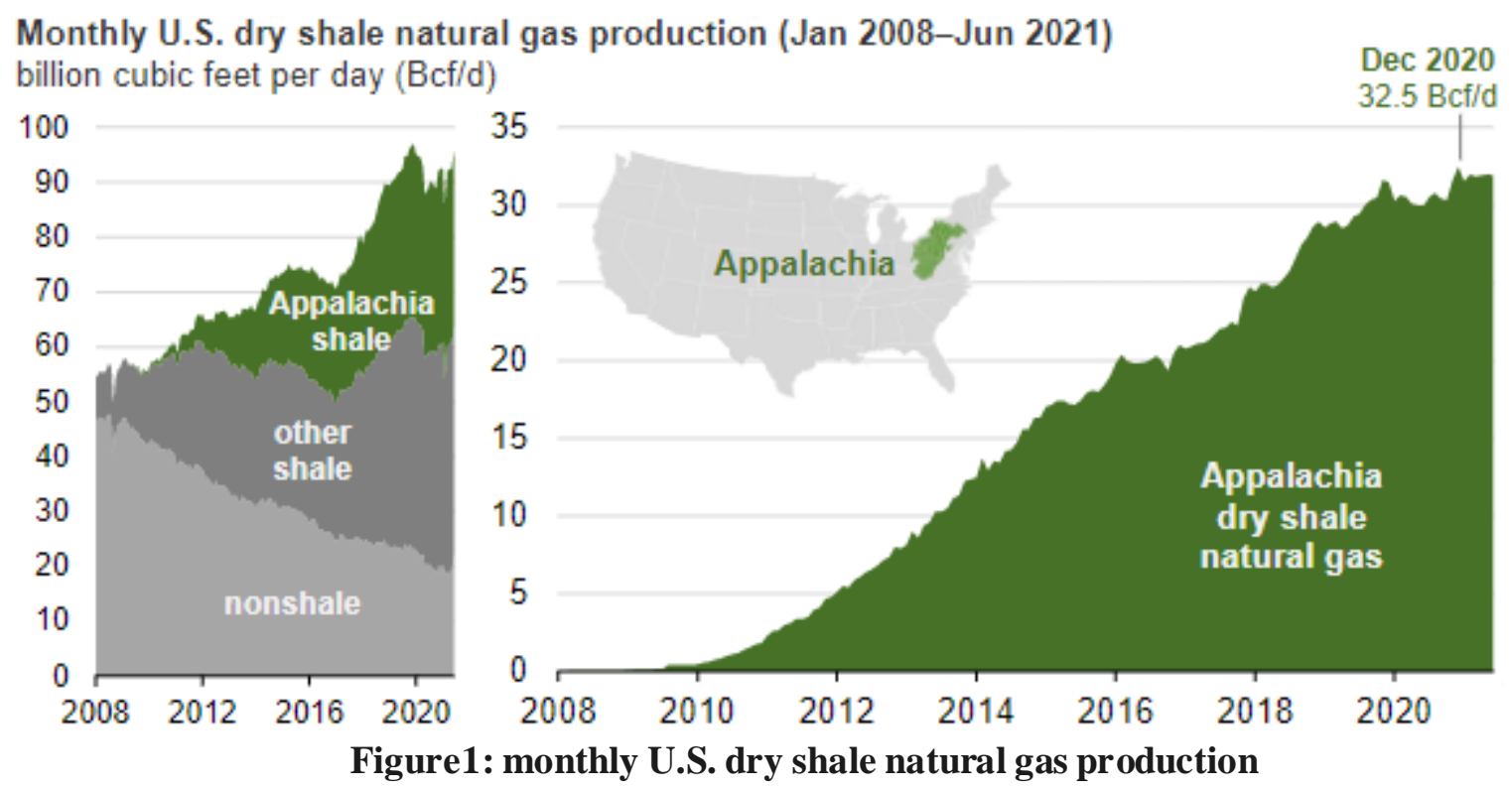

\subsection{Precision Petrophysical Analysis Laboratory (PPAL)}

\subsubsection{PPAL Description}

Figure 2 shows the layout of the PPAL components and how they have been assembled. The core holders are the most essential components. The core holders are solid stainless steel and are positioned in the center of the unit allowing them to warm evenly and maintain a constant temperature. The core sample of about 1 " diameter by 2.5 " in length must be placed in a sleeve made of Viton Synthetic Elastomer to protect them from the water that is used to apply confining pressure tri-axially. This is possible because one of the end caps of the core holder will float and compress the sample axially. An air driven liquid pump (Haskel 4B Series) is used to pressure the water up to a maximum of $10,000 \mathrm{psi}$. The calibrated positive displacement pump is used for displacing gas into the system for volume measurements. Two tanks are used to store gas at upstream and downstream pressure. a numbers of control valves, electric actuators, and sensitive pressure and pressure differential transducers are utilized to automatically control the flow and monitor the pressures. The compact electric heaters, programmable temperature controller, and circulation fans are mounted on the system to maintain the temperature stable within the PPAL enclosure. Data acquisition system, solenoid valves, relays, and a computer with the necessary software (LabView) are used to operate the system and collect the data. 


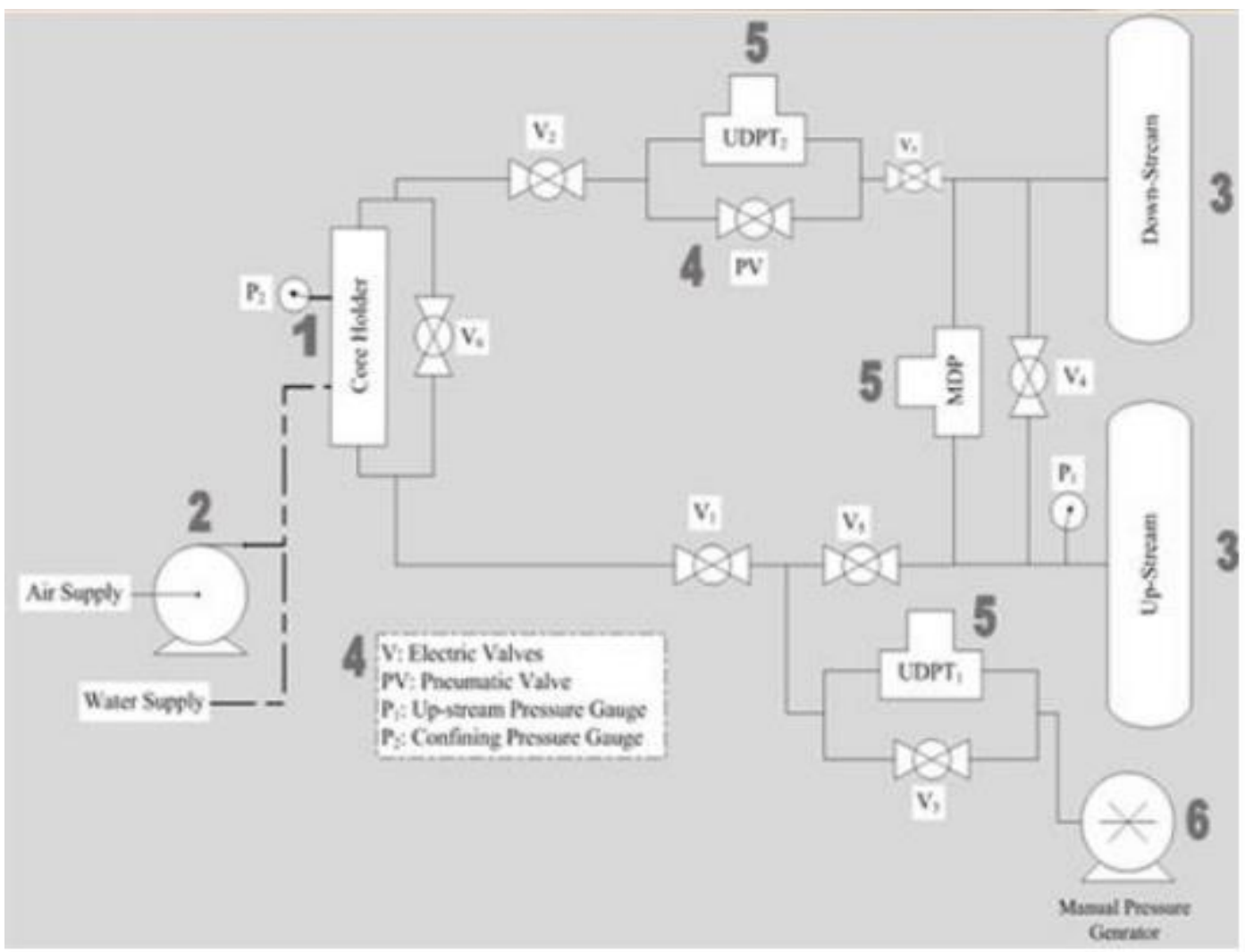

Figure 2: PPAL Layout

\subsubsection{PPAL Operation}

Initially, the blank steel core is placed in the core holder. The confining side is pressurized first. The water line is opened to allow water to pass through the confining pump and into the bottom of the core holders. The valves on top of the core holders are opened until all the air bled out. The top valves are then closed, and the liquid pump is used to increase the confining pressure. Once the desired confining pressure is achieved, the valve after the liquid pump is closed. This separates the pump from the cores, locking the confining pressure in the cores and transducer. The gas is then introduced into the reservoir tanks and the rest of the system. The entire system is brought up to the desired downstream pressure. Then the valve between the two tanks is closed and the upstream tank is pressured up to the desired value (a maximum pressure differential of $30 \mathrm{psi}$ ). The PPAL unit is then enclosed. The heaters are turned on and the desired operating temperature is set. The unit is left un-interrupted for several days until temperature stabilizes. Once brought up to the desired operating temperature, the gas pressures can be fined tuned and adjusted back to the desired set points. 


\subsubsection{Leak Test}

Since the PPAL can measure extremely small flow rates, it is imperative that the lines do not leak and are sealed tight. In order to achieve this, the unit is pressured up to approximately $100 \mathrm{psi}$ of gas and every fitting is saturated in Snoopleak testing liquid. If any leak is found, the fitting is a tightened or, if necessary, replaced. The process is then repeated on $300 \mathrm{psi}$ increments of gas pressure until the maximum operating pressure of $1500 \mathrm{psi}$ is reached. Then, the unit is allowed to reach a stable temperature. Once stable, the unit is left uninterrupted overnight while monitoring system pressure. If the pressure drops over the long period of time, then there is a minor leak that is not visible by the human eye. In this case, each section of the plumbing is isolated with ball valves until the exact section that is leaking could be identified.

\subsubsection{Line Volume Measurements}

Before any testing can begin, the line volumes must be measured. The volumes of the different sections can be measured using Boyle's Law and the sensitive differential pressure transducer. The entire gas line will be pressured to a desired pressure (600psi). Then the valve at the start of the line is closed and the upstream and downstream tanks are isolated. The downstream tank is then bled off until 15 to 30 psi is observed on the main differential transducer between the tanks. The line is now at lower pressure. The last valve is then closed, isolating the line from the downstream tank. At this time the sensitive transducer is evenly pressured with the upstream pressure. The sensitive differential valve is then closed locking the high pressure on one side of the transducer. The valve at the start of the line is then opened releasing the high pressure into the line. The sensitive transducer will be reading full scale. Now the calibrated gas pump is used to pump gas back into the line on one side of the sensitive transducer. Once the sensitive transducer is back to zero, the volume of the displaced gas is the same as the volume of the line. This process can be repeated for each section of the line. This method is similar to that of the porosity measurement, except the steel blank cores are installed in the core holders.

Zamirian (2015) derived an equation to estimate the line volume based on Boyle's law.

$$
V_{D}=\Delta V \frac{P_{U} Z_{D}}{P_{U} Z_{D}-P_{D} Z_{U}}
$$




\section{Where:}

$\mathrm{V}_{\mathrm{D}}$ : Volume of the line.

$\Delta \mathrm{V}$ : Volume of the gas displaced by the positive displacement pump.

PU: Upstream pressure, psi.

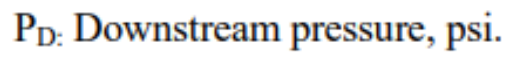

Zu: Upstream compressibility factor.

$Z_{D:}$ Downstream compressibility factor.

\subsubsection{Core Preparation}

The core samples were cut, trimmed, and smoothed to a size of 1 inch diameter and a length of 2 inches. The diameter and length of the samples were measured with the caliper. The plug is then is weighed. The samples were then placed into a relative humidity dryer at $60^{\circ} \mathrm{C}$ with $45 \%$ humidity in order to reach a baseline of water saturation. The samples were removed from the chamber often and weighed to track the changes over time. Over the course of a few days the samples reach a stable weight and are placed in sealed containers.

\subsubsection{Loading the Core Sample}

First, the fixed end of the core holder is removed. The solid end and the large rubber $\mathrm{O}$-ring are lubricated with a thick, clean, petroleum jelly. The supplied rubber Viton sleeve is fit over the greased end. The core sample is then removed from the sealed container and placed in the Viton sleeve. Then, the floating end of the core holder is inserted into the Viton sleeve such that it comes in contact with the core sample. This assembly is then fitted into the coreholder body. Bothends of the coreholder can be screwed in completely. If necessary, a core holder wrench can be used to help seat the O-ring. Once the sample is loaded into the holders, the gas lines can be connected.

\subsubsection{Porosity Measurement}

The same line volume measurement can be done except the blank is replaced with the core sample, and the difference between the volume (VD) calculated by the sample and the blank yields the pore volume. For porosity calculation, it is sufficient to consider the pore volume of the sample, which is added to the line volumes and can be calculated as:

$$
V_{P}=\Delta V \frac{P_{U} Z_{D}}{P_{U} Z_{D}-P_{D} Z_{U}}-V_{D}
$$




\section{Where:}

$\Delta \mathrm{V}$ : Volume of the gas displaced by the positive displacement pump.

$V_{\mathrm{P}}$ : Pore volume of the sample.

$\mathrm{V}_{\mathrm{D}}$ : Volume of the line.

PU: Upstream pressure, psi.

$\mathrm{Z}_{\mathrm{U}}$ : Upstream compressibility factor.

$\mathrm{P}_{\mathrm{D}}$ : Downstream pressure, psi.

$Z_{D}$ : Downstream compressibility factor.

\subsubsection{Permeability Measurement}

The permeability of the core sample is measured by introducing a pressure difference across the core sample to allow the gas to flow. As gas flows from the upstream tank, through the core, and into the small downstream line volume which is separated from the downstream tank by an automated bellow valve. Over time, the pressure in the line builds up. The pressure difference between the line and the downstream tank is measured with an extremely sensitive pressure transducer. The transducer has a maximum differential limit of 0.5 psi. Once the pressure differential reaches $80 \%$ of transducer's full scale, or 0.4 psi, the automated bellow valve opens by a computer signal. This valve stays open just long enough for the line and downstream reservoir tank to reach pressure equilibrium (5 to 10 seconds). The valve is then closed and the pressure buildup is started over. PPAL is capable of measuring extremely low flow rates accurately. The flow rate is determined based on the previously measured volume of the section of the line. The data acquisition system records the pressure buildup in the line over time and the results are used to determine the permeability of the sample under the set conditions (temperature, confining pressure, pore pressure) and these can be averaged for a precise measurement. The permeability of the sample under the set conditions (temperature, confining pressure, pore pressure) is then determined by Darcy's equation. (Zamirian, 2015) derived an equation to calculate the permeability as shown.

$$
k=\frac{2 \mu L V_{L+p} U D P T_{2}}{A \Delta t\left(P_{U}^{2}-\left(P_{D}+U D P T_{2}\right)^{2}\right)}
$$




\section{Where:}

K : Permeability, Darcy

$\mathrm{V}_{\mathrm{L}+\mathrm{P}}$ : Total volume of the downstream section $\left(\mathrm{V}_{6}\right.$ to $\left.\mathrm{PV}\right)$ plus the sample pore volume.

$U D P T_{2}$ : Pressure builds up, atm

$\mu \quad$ : Viscosity, cp

$L \quad$ : Length of the plug, $\mathrm{cm}$

A : Cross section area of the plug, $\mathrm{cm}^{2}$

$P_{D} \quad$ : Down-stream absolute pressure, atm

$P_{U} \quad:$ Up-stream absolute pressure, atm

$\Delta \mathrm{T} \quad$ : Time, second.

\subsubsection{Steady-State Flow Rate Validation}

The objective of building PPAL is to measure shale permeability, which in the range of nano-darcy under a steady-state condition. Therefore, validating the steady-state flow rate across the sample is crucial as a proof of concept. The pressure drops across the sample staying constant over time is a one-dimensional steady-state condition based on Darcy's law (Tarek, 2010). PPAL has two one-gallon gas tanks functions as gas storage for the upstream and downstream pressure, by way of connecting them to the ups tream and downstream ends of the core holder to keep the sufficient pressure at a steady level during experiments. Also, connecting the UDPT2 at downstream allows the pressure to build up a maximum 0.5 Psi in the downstream and then releases the gas to maintain the constant downstream pressure and the steady-state condition. Darcy's law is valid when the flow is linear (Darcy, 1856). Therefore, the linear pressure builds up at UDPT2 indicates a linear flow of gas through the sample which allows us to apply Darcy's law to calculate the permeability.

\subsection{Klinkenberg Correction}

Klinkenberg (1941) demonstrated that the permeability of porous media to gasses is a linear function of the mean reciprocal pressure as shown in Equation below: 


$$
\begin{gathered}
k_{g}=k_{\infty}\left(1+\frac{b_{k}}{\bar{p}}\right) \\
\frac{b_{k}}{\bar{p}}=\frac{4 c \lambda}{r}
\end{gathered}
$$

\section{Where:}

$k_{\infty}$ : absolute (liquid) permeability

$b_{k}$ : slippage factor

$\lambda$ : mean free path of gas molecules, $\mathrm{mm}$.

$r$ : radius of a capillary or a pore, $\mathrm{mm}$.

Klinkenberg's theory considers the momentum carried by the gas molecules hitting the pore walls, gas slippage, which results in higher gas rates and ignores the momentum that gas molecules can carry to the bulk fluid. Moreover, using the focused ion beam scanning electron microscopy (FIB/SEM) has shown that two distinct porous media exist in organic rich shale, i.e. Organic and Inorganic (Ambrose, 2010). A significant portion of the pores associated with gas storage is found within organic materials, or kerogen pockets, which are 200-500 nanometers $(\mathrm{nm})$ in size. The pores in these kerogen pockets are in the range of microspore (less than $2.0 \mathrm{~nm}$ ), and mesopore $(2-50 \mathrm{~nm})$ sizes with the average pore size below $10 \mathrm{~nm}$ (Adesida, 2011). The pore size range indicates that; the organic-rich shale can be considered as a naturally occurring nano-pore material. At this scale, the classical approach of modeling gas flow based on continuum equations may not be valid. Different flow regimes are categorized based on Knudsen number (Roy, 2003):

1. Continuum (viscous) flow $\left(K_{n}<0.001\right)$.

2. Slip flow $\left(0.001<K_{n}<0.1\right)$.

3. Transition flow $(0.1<K n<10)$ : In this regime, a combination of slip and diffusion flow occurs.

4. Free molecular flow $(K n>10)$.

Where Knudsen number $(\mathrm{Kn})$ as illustrate in Figure 4, is defined as the ratio of molecular mean free path to a characteristic length of pores $(\mathrm{L})$ :

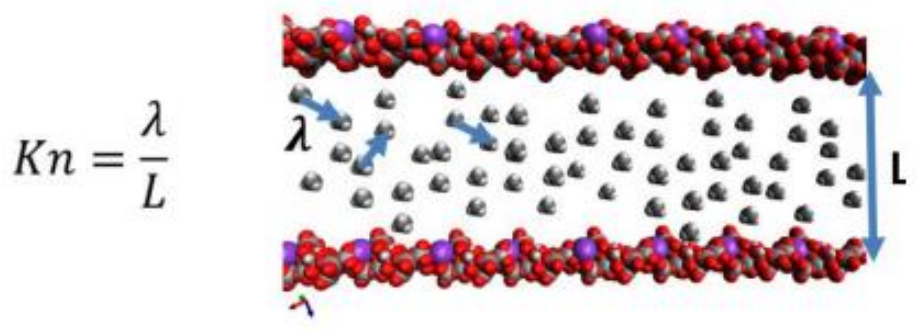




\subsubsection{Double Slippage Correction}

Recently, Fathi (2012) incorporated the momentum carried by bouncing back molecules was into the slip flow leading to a linear relation between permeability and reciprocal of square of pressure (double slippage correction) as follows:

$$
k_{g}=k_{\infty}\left[1+\left(\frac{b_{k}}{p}\right)^{2} \frac{L_{K e}}{\lambda}\right]
$$

Where Lke is a length scale associated with the kinetic energy of the bouncing-back molecules. The doubleslippage affect can lead to measured permeability values that are even higher than those predicted by Klinkenberg theory at low pressures. Others have observed this phenomenon where the higher gas flow was inadvertently attributed to turbulent flow in nano-pores at low pressures (Rushing, 2004), while the impact of the turbulent flow in shale due to a very low Reynolds number is negligible as compared to gas slippage effects at low pressures (Wu, 1998). 14 Ashish (2016) conduct a set of experiments to characterize the flow regime in shales for gas permeability measurements over different pore pressure ranges and conclude:

1. Pore pressure $\leq 250 \mathrm{psi}$; transition flow is dominant and double slippage correction are required.

2. Pore pressure $\approx 1000 \mathrm{psi}$; slip flow is prevalent and Klinkenberg correction can be used to determine the absolute permeability

3. Pore pressure $\geq 2000 \mathrm{psi}$; the correction in permeability values is negligible.

\subsection{Effect of Stress on the Porosity and Permeability}

The reason for these different behaviors can be related to the nature of the shale. Shale is known as naturally fractured formations. Beside the fractures, shale contains organic material known as kerogen in their matrix media. Thus, each media has its porosity and permeability, generally speaking, a permeability of fracture is higher than a permeability of the matrix due to the higher conductivity in fractures, while porosity of the matrix is greater than the porosity of fracture due to its higher storage capacity. In other words, when a sample, which is a combination of these two media, undergoes porosity and permeability tests, matrix plays the dominant role in porosity measurement, while the fracture plays the dominant role in permeability measurement. By knowing this, it can be explained that porosity did not show hysteresis because pores in 
the matrix media have not lost their volume, and grains are not damaged or crushed. On the other hand, the fractures, which play the dominant role in permeability, did not open completely after the stress was released, which caused permeability hysteresis (Zamirian, 2015). In regard to (Walsh J. B., 1981), the relationshipbetween both porosity and permeability versus stress, especially in fractured formations, should be a power law, exponential, logarithmic or even polynomial due to the fractures that play the dominant role in total permeability of the rock. Zamirian et al. (2015a) was performed a set of experiments on the shale sample to investigate the effect of stress on porosity and permeability. However, results show permeability is very sensitive to stress while porosity is impacted by stress to a lesser extent. Also, the impact of stress on permeability is an irreversible process but permeability will not return to its initial value. 


\section{Chapter3}

\section{Objective and methodology}

The objective of this study is to analyze and investigate the impact of pore and confining pressures on the porosity and the permeability and effect of adsorption and desorption on permeability using Helium and Nitrogen and calculating the absolute permeability of the two different Marcellus Shale samples and perform a comparison between the two samples, the first sample is (F2HA) from quarry shaly limestone from horizontal well, The other sample used in this study were made available through the Marcellus Shale Energy and Environment Laboratory (MSEEL), a dedicated field laboratory in the Marcellus Shale. MSEEL has been established to undertake field and laboratory research to advance and demonstrate new subsurface technologies and to enable surface environmental studies related to unconventional en ergy development. The filed site is owned and operated by Northeast Natural Energy, LLC and contains several horizontal Marcellus Shale wells. In addition, a vertical well has been drilled specifically for obtaining core, $\log$, and other data for scientific purposes (science well).

\subsection{Impact of the Pore Pressure on Permeability (Slippage Effect)}

A set of the permeability experiments for the two samples were performed with Helium and Nitrogen adsorption and desorption to determine the absolute permeability of the core plug. The measured permeability must be corrected for the slippage effect. The absolute permeability could be determined by changing the gas pressure under constant net stress conditions. The permeability measurements were performed different gas (pore) pressures for Helium and Nitrogen while the net stress was maintained constant, Both Klinkenberg and double slippage corrections were applied to the results to evaluate the absolute permeability of the sample and to confirm the flow regime during the experiments.

\subsection{Adsorption/Desorption Effect on Permeability}

The permeability experiments were repeated with Nitrogen by increasing the gas pressure (adsorption) and by decreasing the gas pressure (desorption). All the experiments were performed under constant net stress. It should be noted as the gas pressure is increased (or decreased), the gas can be adsorbed to (or desorbed from) the sample. Therefore, the flow rate during this experiment is monitored to establish constant flow rate (sample saturation with gas) at each gas pressure. The final stabilized flow rate is then used for evaluating the permeability. The absolute permeability can be determined by applying slippage correction.

The absolute permeability was determined from the measurements with Nitrogen (both adsorption and 
desorption) and were compared against the absolute permeability value that were determined from the measurements with Helium. This would allow to evaluate the impact of adsorption/desorption on the permeability measurement results.

\subsection{Stress Effect on Permeability and Porosity}

To investigate the impact of stress, a set of porosity and permeability experiments under different net stresses were performed while the average gas pressure was maintained constant. The entire set of experiments consisted Runs with Nitrogen, with different confining pressures increasing sequentially, and other runs sequentially decreasing pressures while gas pressure remains constant. 


\section{Chapter 4}

\section{Result and Discussion}

\subsection{Impact of the Pore Pressure on Permeability}

Two gases of Helium and Nitrogen were used separately to measure the permeability at adsorption and desorption stages, all tests were done at constant net stress (4000 psia) for MSEEL sample and (560 psia) for F2HA sample. For this sample, experiments were started with $\mathrm{He}$, and after a sequence of adsorption and desorption steps, it was repeated by Nitrogen. Figure 3, Figure 4 and Figure 5 shows the result of gas pressure effect on permeability. It is clearly evident from figure 4 and Figure 5 for both samples that lower pressures result in higher measured permeability values (more gas slippage). However, the absolute permeability is an intrinsic property reflecting the internal structure of the rock. That means permeability of the rock is a constant value no matter what pressure is used. For both Helium and Nitrogen for sample F2HA no hysteresis was observed after the desorption test shown in Figure 5. for both samples Helium shows higher permeability than Nitrogen. Smaller molecular size of Helium respect to Nitrogen, causes higher Knudsen number and more gas slippage and therefore, higher gas permeability at the same condition. For MSEEL sample there is a little hysteresis as shown in Figure 4, probably MSEEL sample has more TOC percentage than F2HA which cause Nitrogen adsorption effect on permeability.

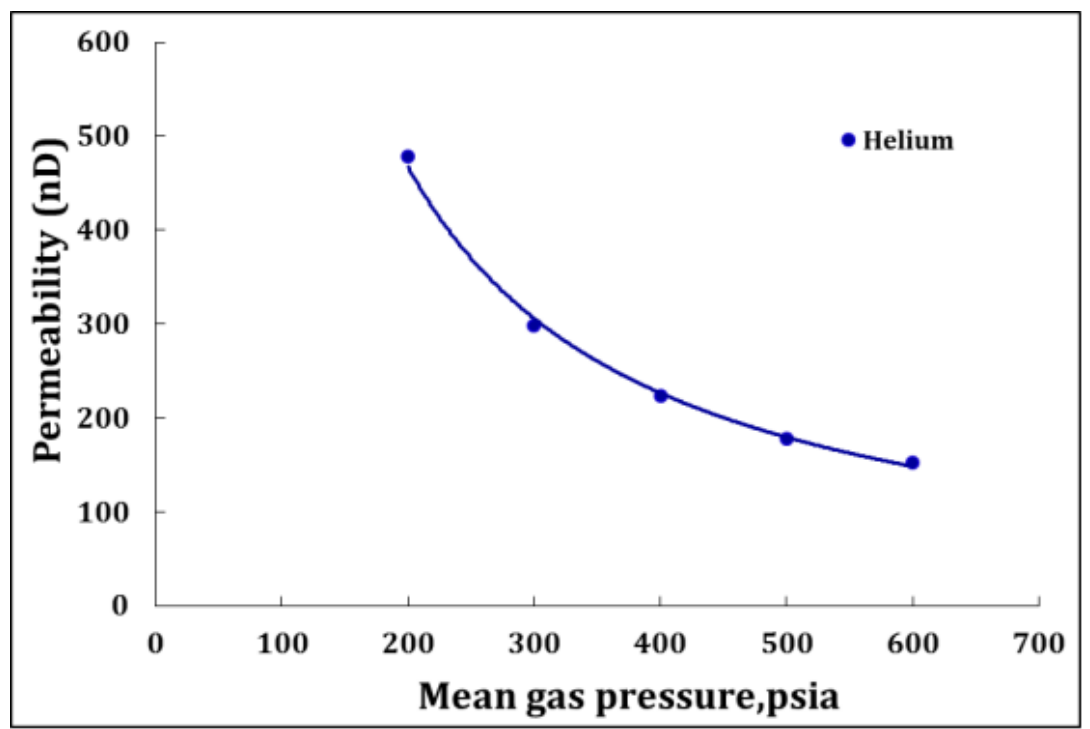

Figure 3: Gas pressure (slippage) effect on permeability using Helium, (MSEEL) 


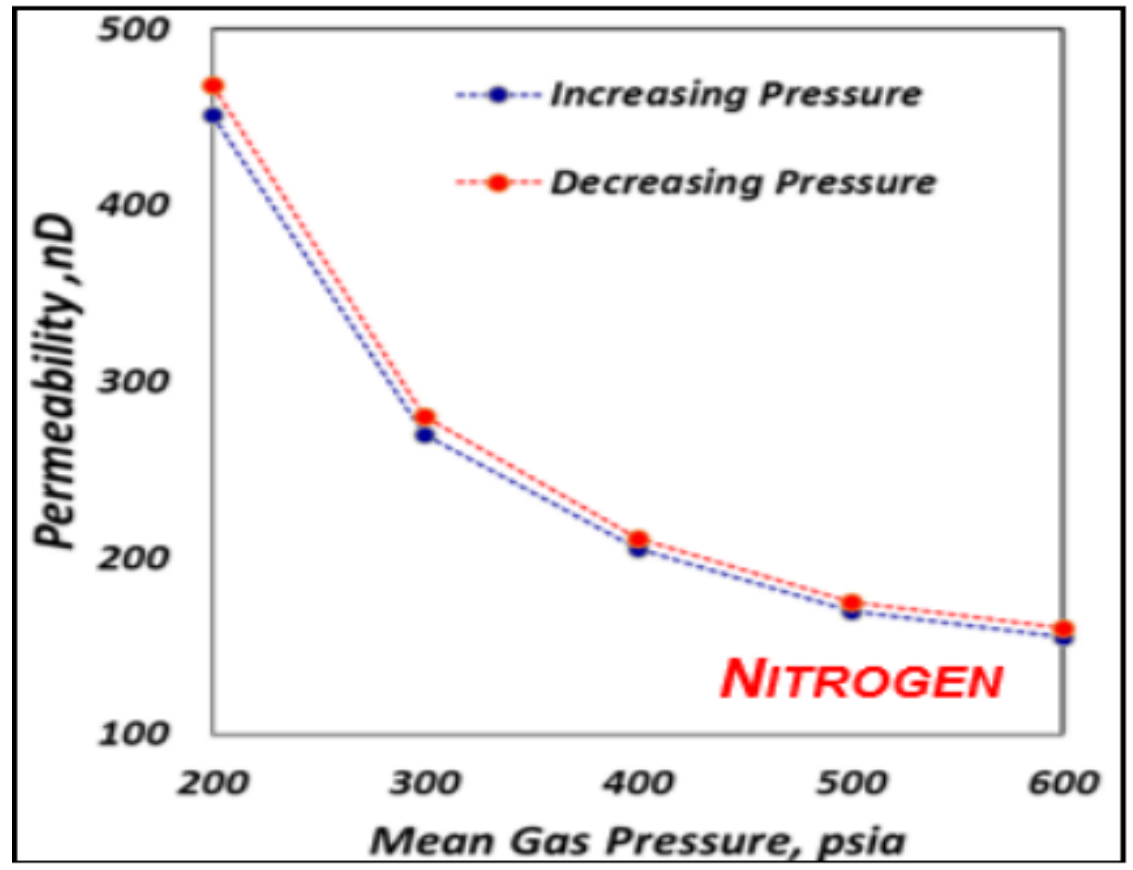

Figure 4: Adsorption/Desorption effect on permeability using Nitrogen, (MSEEL)

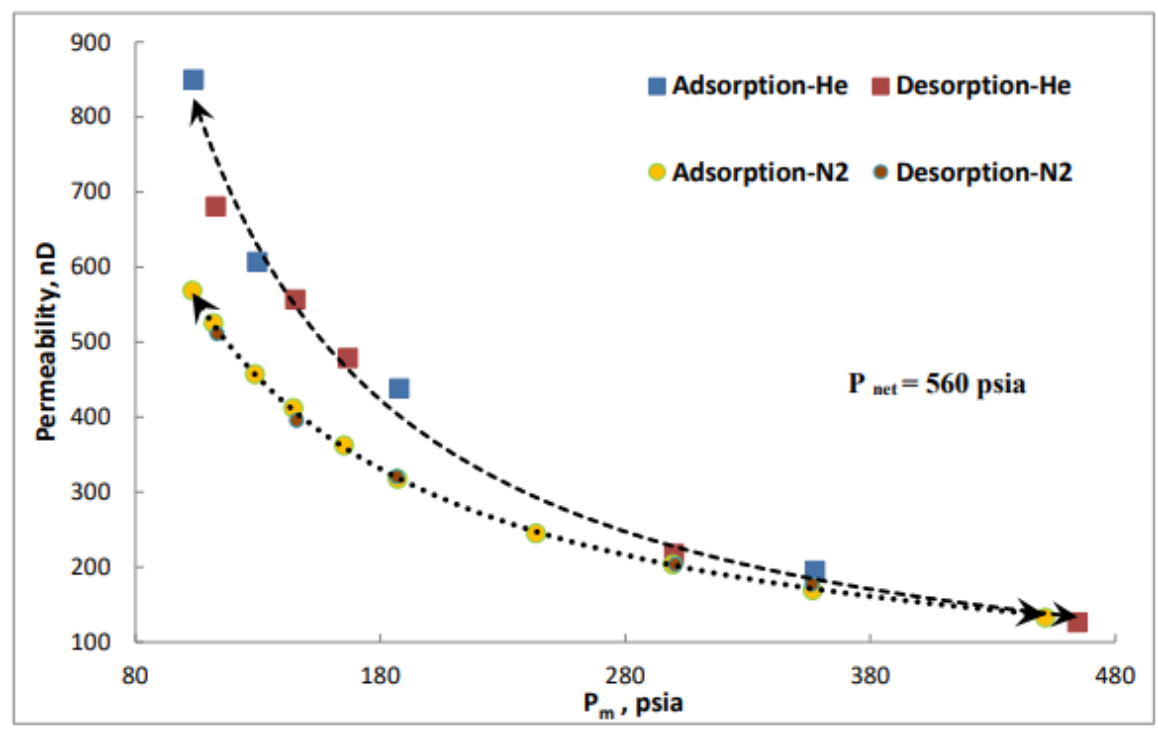

Figure 5: Adsorption/Desorption effect on permeability using Helium and Nitrogen, (F2HA) 


\subsection{Absolute Permeability Determination}

The application of Klinkenberg correction to the measured permeability values with Helium for both samples results in a negative absolute permeability value. This value is of course not correct, which suggest the flow regime is Transition flow due to small pores sizes. The double slippage correction as illustrated in Figure 6 and Figure 8 results in a value of $124 \mathrm{nD}$ for MSEEL sample and $154.3 \mathrm{nD}$ for F2HA sample.

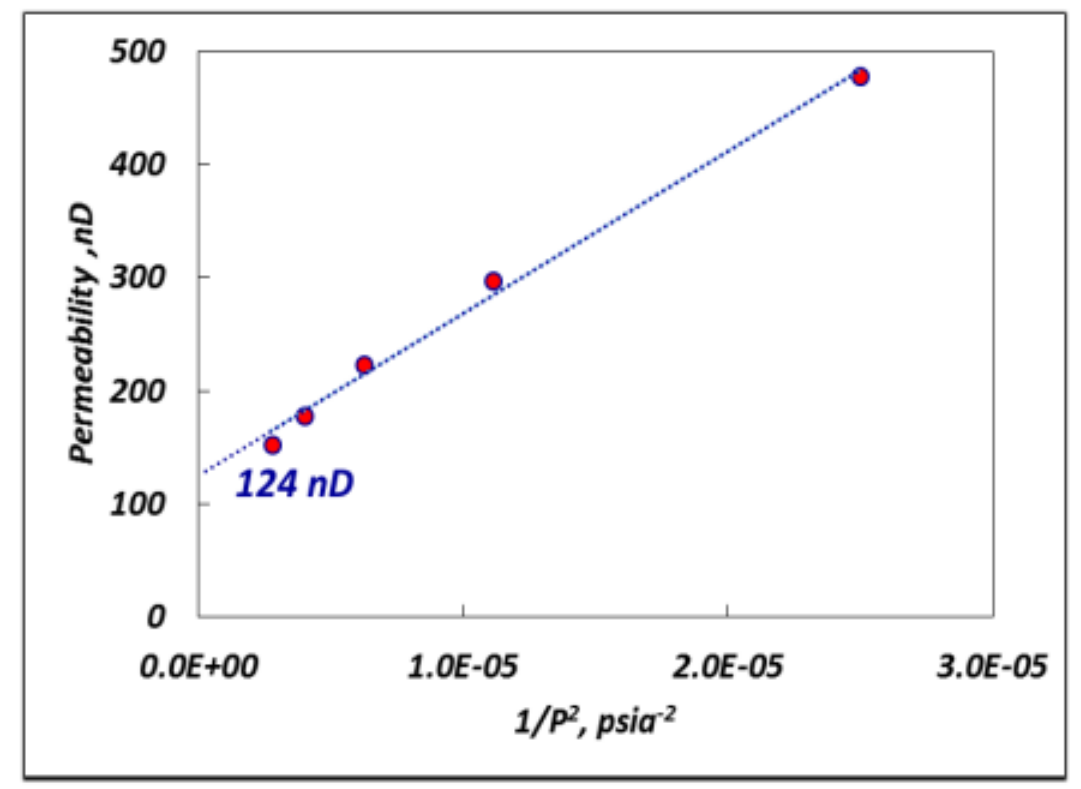

Figure 6: Double slippage correction on gas permeability using Helium, (MSEEL)

\subsection{Adsorption/Desorption Effect on Permeability}

Nitrogen was used to measure adsorption and desorption effect on the permeability for both samples. All the experiments were performed at constant net stress (4000 psia) for MSEEL sample and (560 psia) for F2HA sample Figure 7 and Figure 8 shows the absolute permeability values obtained by applying double slippage correction. The value of the absolute permeability measured by Nitrogen adsorption and Nitrogen desorption are same $(114 \mathrm{nD})$ for MSEEL sample and (155.51 nD) for F2HA sample and smaller than value measured by Helium at the same net stress. This can be attributed to Nitrogen adsorption on the core plug which causes a reduction in pore diameters. The results confirm that the absolute permeability, is 
independent of the gas type as long as the experiment is performed at the same stress condition and gases has no adsorption effect due to its low TOC.

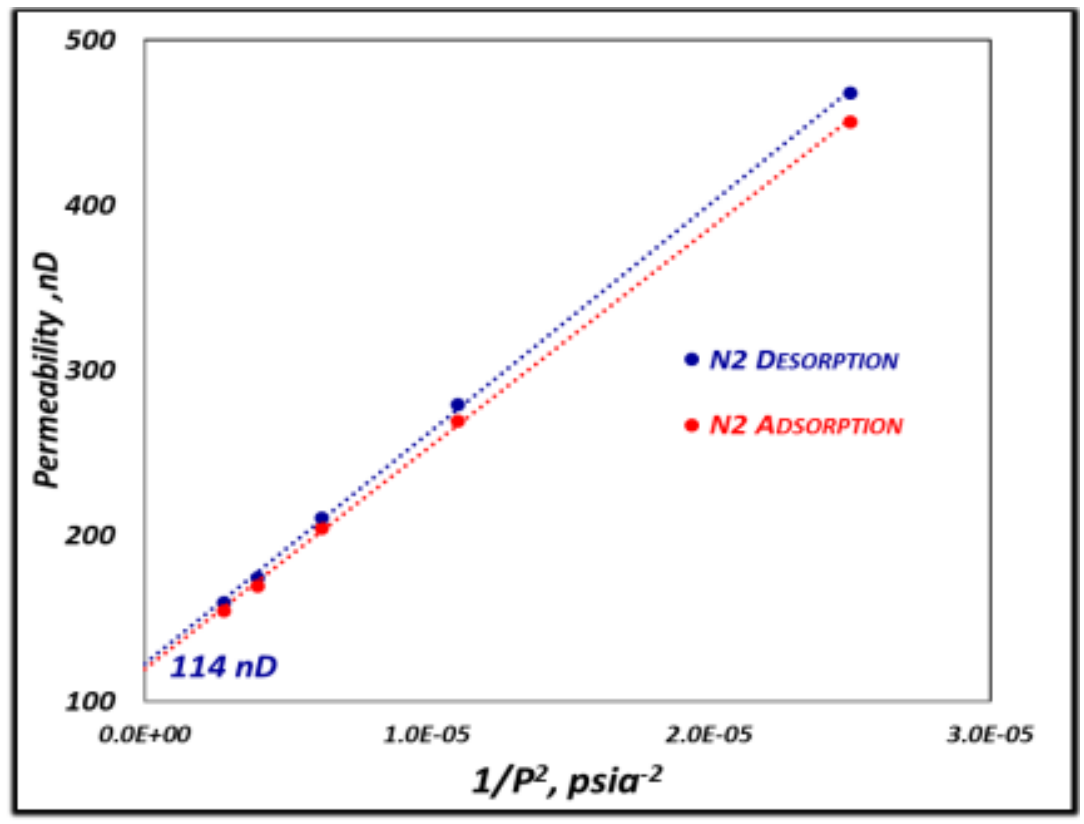

Figure 7: Adsorption/Desorption Effect on Permeability using Nitrogen, (MSEEL)

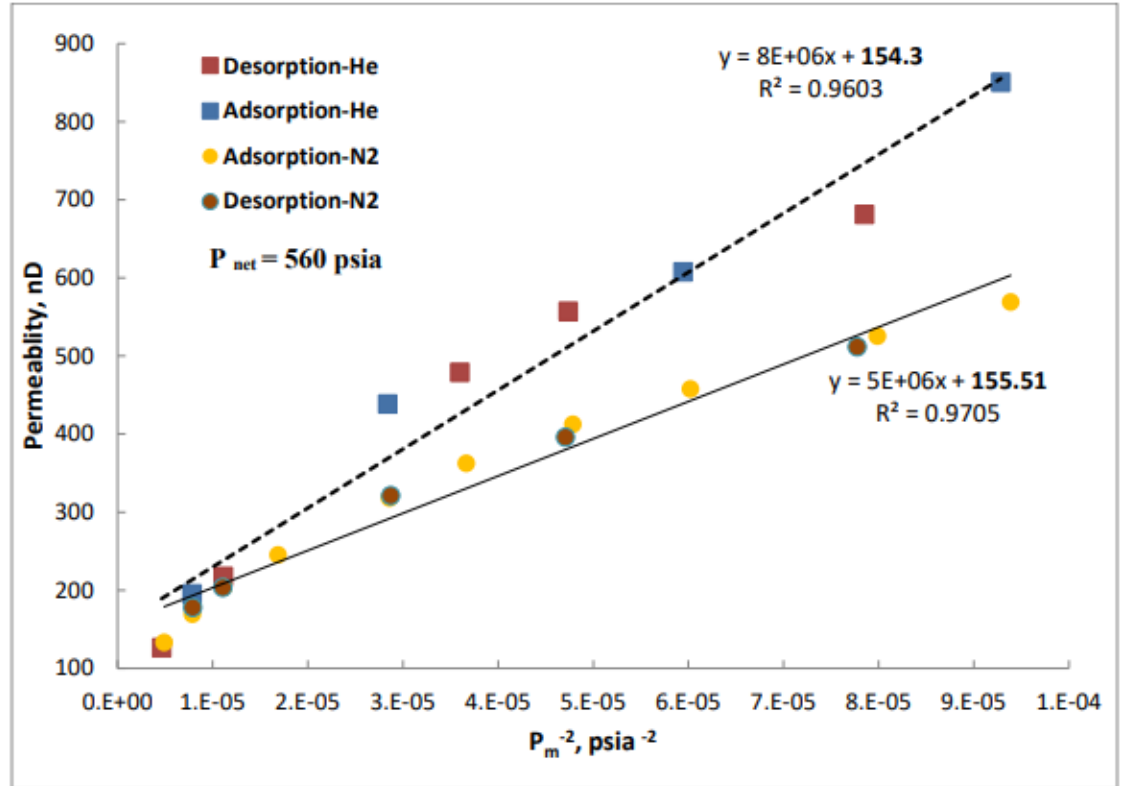

Figure 8: Double slippage correction on Helium and Nitrogen measurements, (F2HA) 


\subsection{Stress Effect on Permeability using Nitrogen}

For both samples Figure 9 and Figure 10 indicates that when confining pressure is increased, the permeability has decreased dramatically. On the other hand, as the confining pressure was decreased, the permeability increased. However, the permeability did not regain its initial value resulting in permeability hysteresis with stress. From Figure 9 and Figure 10 the results indicate that the shale has an elasticity behavior for MSEEL sample the last permeability value when confining pressure was decreased lost $20 \%$ of its initial value on the other hand for F2HA sample the permeability lost $50 \%$ of its initial value which suggested that the MSEEL sample has more elasticity than F2HA sample.

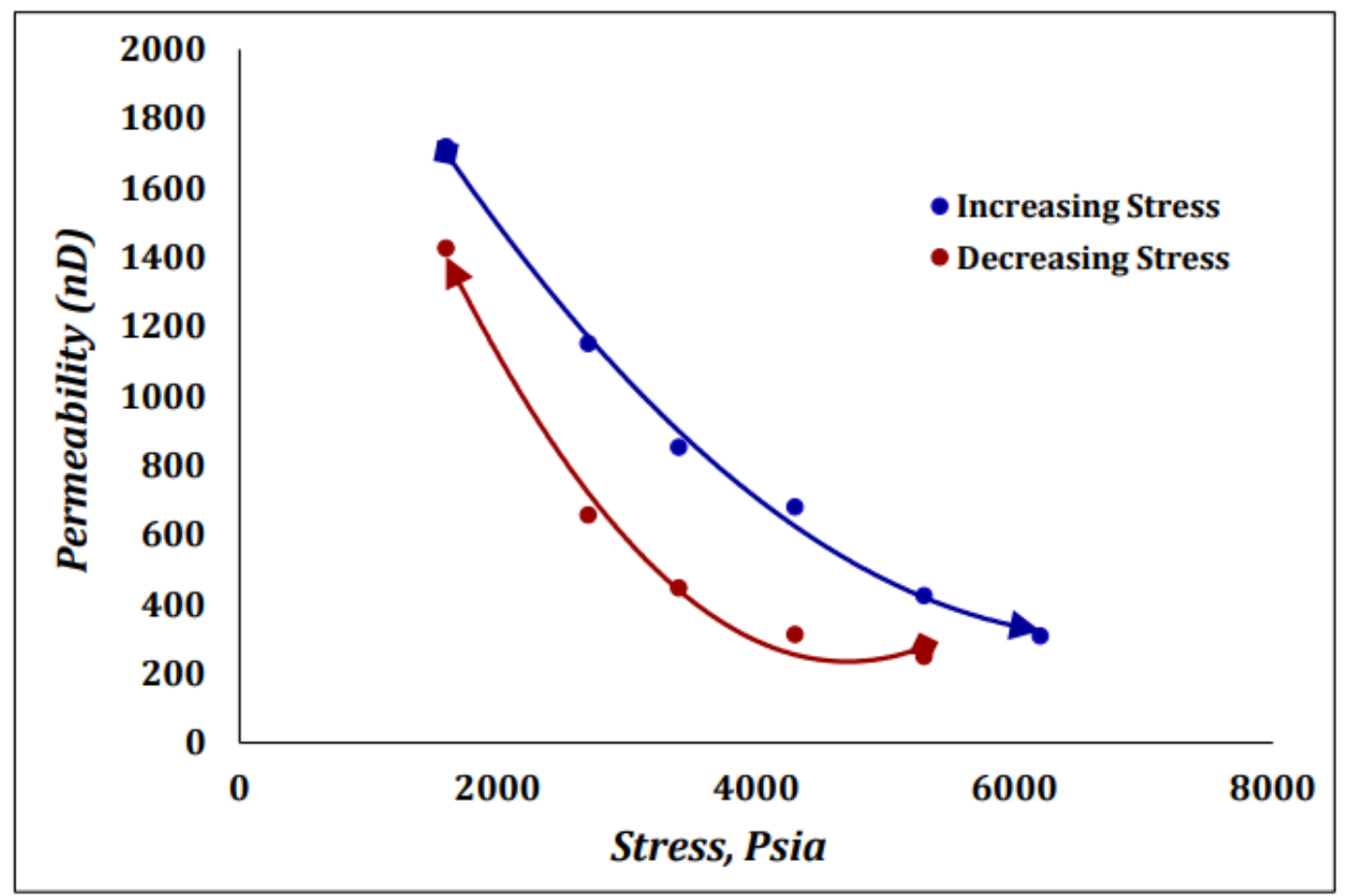

Figure 9: Stress Effect on Permeability using Nitrogen, (MSEEL) 


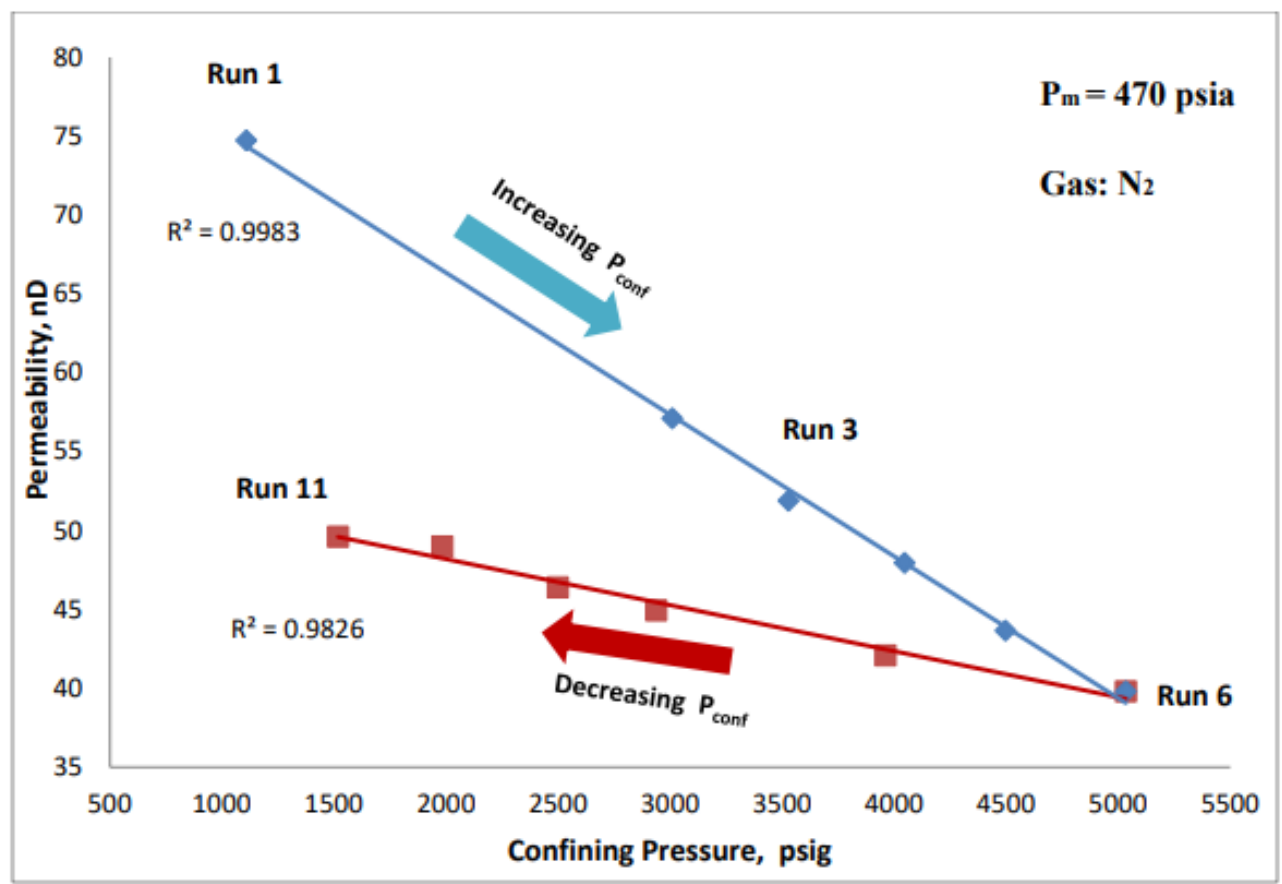

Figure 10: Effect of stress on permeability using Nitrogen, (F2HA)

\subsection{Stress Effect on Porosity using Nitrogen}

The porosity of both samples was simultaneously measured during the aforementioned permeability measurement Runs to evaluate the stress effect on the porosity. The results are illustrated in Figure 11 and Figure 12. As it can be observed, the porosity varies with stress in a linear trend. The reduction in porosity is less severe than the permeability. Moreover, after decreasing the confining pressure, the porosity for MSEEL sample approximately regained its initial value and did not exhibit any hysteresis. On the other hand, for F2HA sample the porosity retained its initial value and also did not show any hysteresis. The reason behind these two different behaviors comes back to the nature of shales. Shales are known as naturally fractured formations. Beside the fractures, shales contain organic material known as kerogen in their matrix media. Thus, each media has its own porosity and permeability. Generally speaking, permeability of fracture is higher than permeability of matrix due to the higher conductivity in fractures, while porosity of matrix is higher than the porosity of fracture due to its higher storage capacity. In other words, when a sample, as a combination of these two media, is gone under porosity and permeability tests, matrix plays the dominant role in porosity measurement, while fracture plays the dominant role in permeability measurement. Knowing this, it can be explained porosity did not show hysteresis because 
pores in the matrix media has not lost their volume and grains are not damaged or crushed. Although, the fractures which play the dominant role in permeability did not open completely after the stress was released on the sample which caused hysteresis. From these results we can suggest that a damage to the matrix of MSEEL sample has occurred which cause the porosity to not regain its initial value exactly.

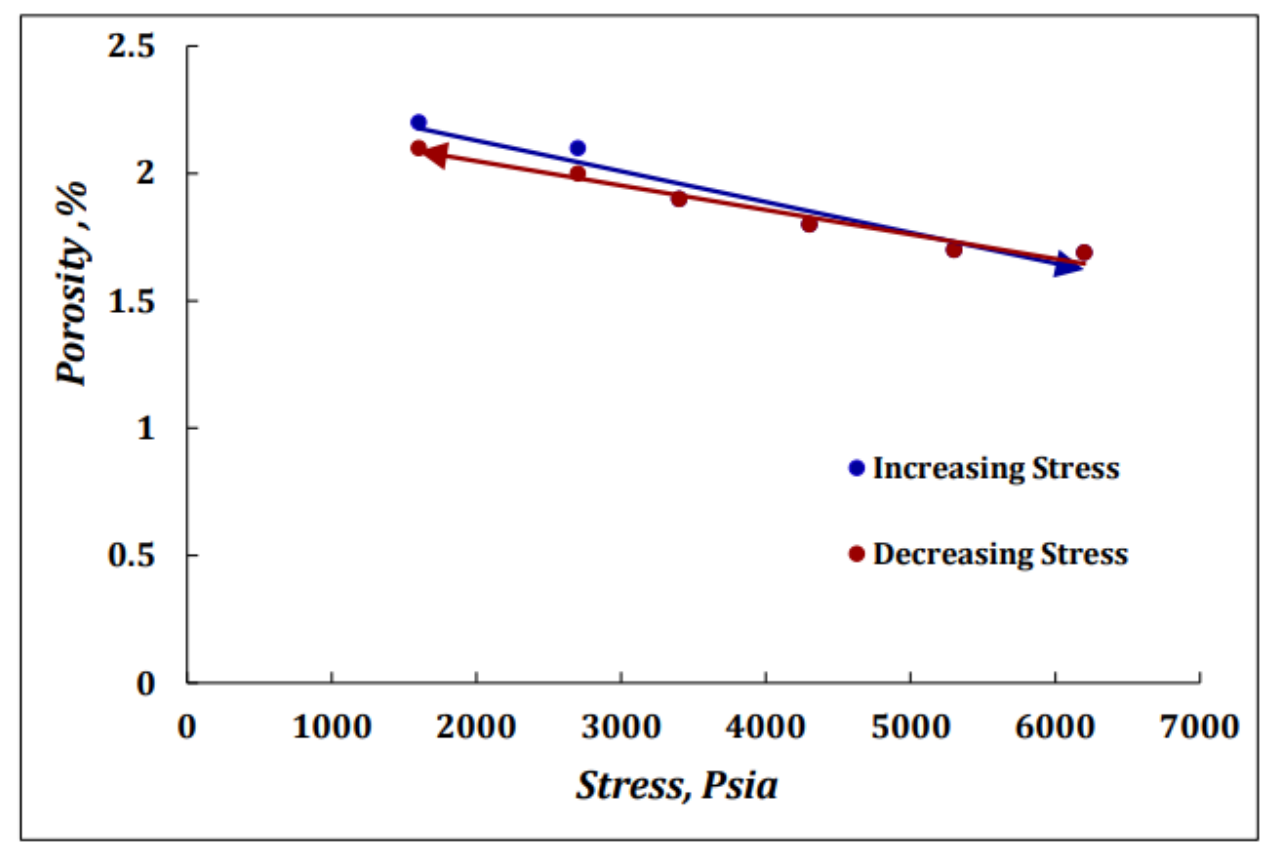

Figure 11: Stress effect on porosity using Nitrogen, (MSEEL)

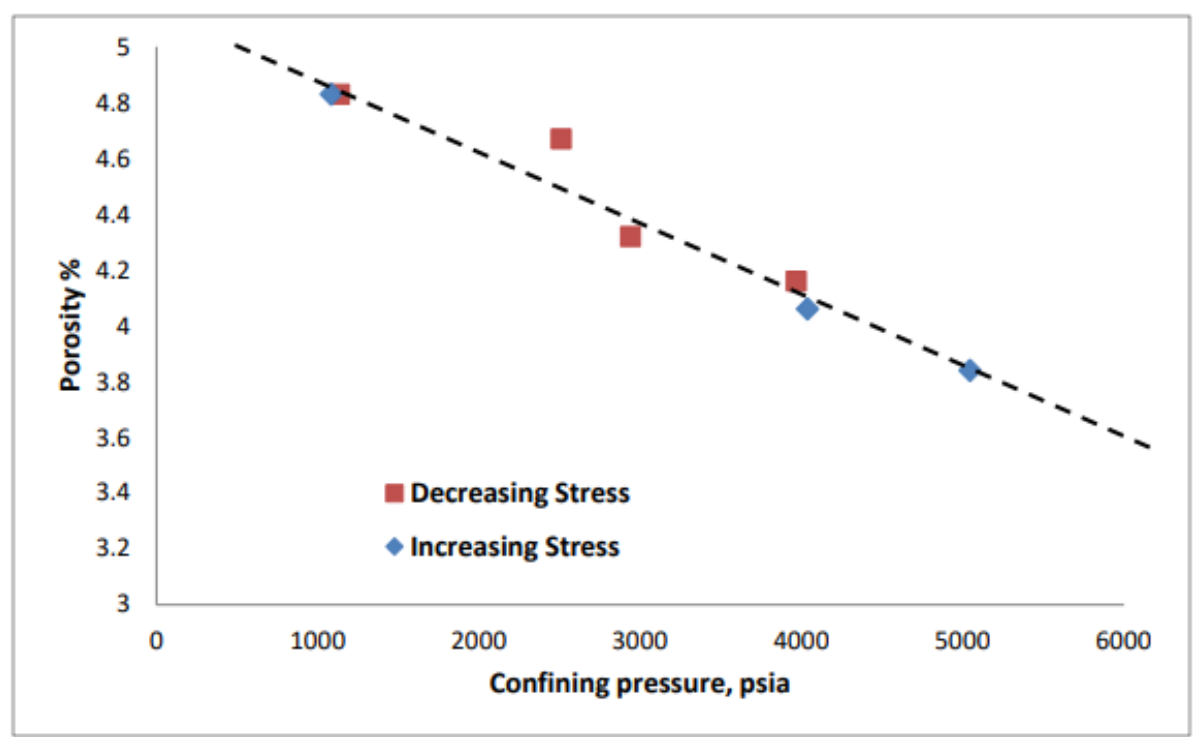

Figure 12: Stress effect on porosity using Nitrogen, (F2HA) 


\section{Chapter 5}

\section{Conclusions}

- When evaluating the impact of pore pressure on permeability no hysteresis was observed after desorption for both Helium and Nitrogen in F2HA sample, but a little hysteresis was found in MSEEL sample which conclude that the MSEEL sample has more TOC percentage than F2HA which cause Nitrogen adsorption effect on permeability.

- The value of the absolute permeability measured by Nitrogen adsorption and Nitrogen desorption is smaller than value measured by Helium at the same net stress. This can be attributed to Nitrogen adsorption on the core plug whichcauses a reduction in pore diameters. And the Helium considered as ideal gas which has no effect on permeability.

- For both samples the value of the absolute permeability measured by Nitrogen adsorption and Nitrogen desorption are same and gases has no adsorption effect due to its low TOC.

- When evaluating stress effect on permeability both samples show hysteresis but MSEEL sample shows less hysteresis than F2HA which suggested that MSEEL sample has more elasticity than F2HA.

- matrix plays the dominant role in porosity measurement, while fracture plays the dominant role in permeability measurement.

- Stress effect on porosity did not show any hysteresis sample F2HA regain its initial porosity value but MSEEL sample approximately regain its initial value which suggest that a damage was occurred to sample matrix.

- The permeability and the porosity of the shale core plug can successfully be measured with PPAL.

- PPAL can provide fast, repeatable, and consistent results.

- Klinkenberg correction fails to provide reliable values for the absolute permeability of the shale sample

- Double slippage correction provides accurate and reliable values for the absolute permeability which confirms that gas flow through shale is in transition flow regime.

- Stress has a significant impact on shale permeability and resulting in hysteresis with increasing and decreasing stress values.

- Stress has a minor impact on the shale porosity. 


\section{References}

1. Adesida, A. A. (2011). Characterization of Barnett Shale Kerogen Pore Size Distribution using DFT Analysis and Grand Canonical Monte Carlo Simulations. SPE Annual Technical Conference and Exhibition, 30 October-2 November,. Denver,Colorado.

2. Ashish Mathur, Carl H. Sondergeld, and Chandra S. Rai., 2016. Comparison of Steady-State and Transient Methods for Measuring Shale Permeability. Paper SPE 180259-MS presented at the SPE Low Perm Symposium held in Denver, Colorado, USA, 5-6 May 2016.

3. Zamirian, M., Aminian, K., Ameri, S., 2015a. Measurement of Key Shale Petrophysical Properties. Paper SPE 174968-MS presented at the SPE Annual Technical Conference and Exhibition held in Houston, Texas, USA, 28-30 September 2015.

4. Zamirian, M. (2015). New Experimental Approach to Measure Petrophysical Properties of Organic-Rich Shales. PHD Dissertation.

5. Zamirian, M., Aminian, K., Ameri, S., Fathi, E., 2014a. A New Steady State Experimental Technique for Shale Permeability Measurement. Paper SPE 171613-MS presented at the Unconventional Resources Conference, Calgary, Alberta, 30 September- 1 October.

6. Klinkenberg, L. (1941). The Permeability of Porous Media to Liquid and Gases. API Drilling and Production Practices, 200-213.

7. Tarek, A. (2010). Darcy's Law. In Reservoir Engineering Handbook (pp. 341 -343). Oxford, UK: Gulf Professional Publishing.

8. Fathi, E., Tinni, A., and Akkutlu, Y., 2012. Correction to Klinkenberg Slip Theory for Gas Dynamics in Nano-Capillaries. Intl. Journal of Coal Geol. 103, 51-59.

9. Mohamed Elsaig. (2016). Characterizations of the Marcellus Shale Petrophysical Properties. M.S. thesis. 